\title{
Throwing a glance at 100 volumes of a journal and at half a century of its existence
}

\section{Karl Heinrich Hofmann ${ }^{1,2}$. Jimmie Don Lawson ${ }^{3}$}

Received: 20 July 2019 / Accepted: 29 September 2019 / Published online: 19 November 2019

(c) Springer Science+Business Media, LLC, part of Springer Nature 2019

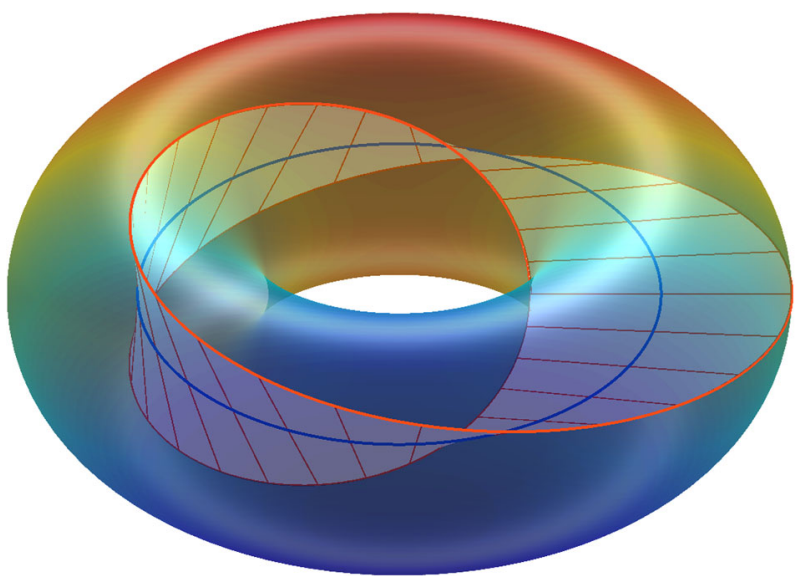

Every highschool student recognizes a Möbius strip, and one out of two mathematical institutions has it in its logo. Indeed every science museum shows you a large model of this surface and moves a tiny vehicle along the blue median to make the visitor realize how it fails to have two sides. But if you really understand its algebra, topology, analysis and its geometry and you therefore comprehend its associative multiplication (which is continuous, differentiable and induced by the semigroup multiplication of

\section{Communicated by László Márki.}

Karl Heinrich Hofmann

hofmann@mathematik.tu-darmstadt.de; khh@math.tulane.edu

Jimmie Don Lawson

lawson@math.lsu.edu

1 Fachbereich Mathematik, Technische Universität Darmstadt, Schlossgartenstrasse 7, 64289 Darmstadt, Germany

2 Department of Mathematics, Tulane University, New Orleans, LA 70118-5034, USA

3 Department of Mathematics, Louisiana State University, Baton Rouge, LA 70810, USA 
$\mathbb{C}^{\times} \times \mathbb{S}^{1}$ )— then you very likely are a reader of the lead journal in the market place for semigroups and their features, namely:

\section{Semigroup Forum}

Its first issue was published by Springer-Verlag New York, Inc., 175 Fifth Avenue, New York, in March 1970 containing four articles received by its editorial board during 1969.

Looking back at this event in 2019 , we are motivated to pause and contemplate a stirring history spanning over half-a-century of a pioneering mathematical journalunconventional in so many significant ways.

In a world that was deeply split politically (and, to an extent, culturally) into two political camps, the first issue of Semigroup Forum in 1970 listed editors from the United States, the Soviet Union, France, Japan, Czechoslovakia, the Federal Republic of Germany ("west"), the German Democratic Republic ("east"), and Hungary, thus shedding light on a group of mathematical scholars who clearly meant to transcend political boundaries. ${ }^{1}$ The authors of the very first issue were BORIS Moiseevich Schein (Saratov, USSR), ${ }^{2}$ Walter Douglas Munn (Stirling, Scotland), TAKAYUKi TAMURA (Davis, California), J. HARVEY CARruth and Jimmie D. LAWSON (Knoxville, Tennessee).

In a period of increasing specialisation, the first decade of this journal had been typically characterized by its concentration on the algebraic and topological theory of semigroups plus an occasional excursion into their harmonic analysis and representation theory. Yet during the second decade of its existence the editorial board had the wisdom of widening the journal's horizon to include HILLE-PHILIPS type operator semigroups. An early article appeared in Volume 29. ${ }^{3}$ A step in this direction had been anticipated for some time by the presence of JEROME A. GOLDSTEIN on the editorial board since 1982. Nevertheless the extension of the journal's scope in this direction of analysis caused some controversy and provoked some lively discussions within the editorial community. But despite this notable expansion the journal has over the years kept its focus on semigroups and their applications (such as semigroup-oriented results from number theory, universal algebra, and other parts of algebra), and has avoided drifting into neighboring topics such as group and ring theory (except for investigations into clearly semigroup aspects of rings like factorization).

At the time of its foundation, Semigroup Forum fully represented its publisher's idea in the early sixties that new and original contributions to mathematical research should appear without delay. In the past such delay had been caused by all publishers insisting on a stylistically polished form and by the implementation of the often complicated mathematical typography. But already Springer-Verlag had introduced in 1964 its Series of Lecture Notes in Mathematics, popular still today, which were

\footnotetext{
${ }^{1}$ For a deeper analysis of the historical background see e.g. [4,11,13,14].

2 In his semigroup network, the size of his 60 page essay was not uncommon. Friends used to measure the length of his communications in units of $1 \mathrm{sch}=20 \mathrm{pp}$. So the dimension of his paper was only $3 \mathrm{sch}$ after all!

${ }^{3}$ F. Neubrander, Well-Posedness of Abstract Cauchy Problems, Semigroup Forum 29 (1984), 75-85.
} 
initially reproduced via offset printing directly from authors' typescripts. ${ }^{4}$ So, for the first two decades of its existence from 1970 until about 1990, Semigroup Forum was published by photo reproduction from camera-ready authors' manuscripts, for whose preparation the authors were instructed in detail in each issue of the journal. ${ }^{5}$ That being said, both the individual editors and the Managing Editors frequently went out of the way to aid authors, especially those working in challenging environments, with various kinds of support, from typing to retyping manuscripts to assistance in achieving reasonably good English to some mathematical coaching for younger researchers. Such efforts helped promote research and interaction in the international community during the early years. Some degree of personal contact and interaction has persisted to the current time, as the Editorial Board has so far resisted pressures to move to an automated editorial management system, preferring rather individual contact through email with authors and referees.

The publication of Semigroup Forum from camera-ready authors' manuscripts in the early years resulted not only in rapid publication, but also in significantly reduced publication costs. The cheaper subscription prices, the quick access to recent research, and the concentration of articles in one's area of interest made the journal quite attractive to researchers in the semigroup community, and promoted the early growth of the journal both from numerous personal subscriptions and from successful efforts to add it to local university subscriptions. Quick publication and wide distribution to the semigroup community also made the journal attractive to authors, from seasoned researchers to newly minted PhDs. Indeed the latter benefitted in launching their careers from the quicker and wider distribution of their work.

In 1989, an article by HI TEX MUROF [15] opened up the digital age for the journal. It explicitly proposed author-generated typesetting of articles via DONALD KNUTH's programming language $\mathrm{T}_{\mathrm{E}} \mathrm{X}$ and indeed laid down the concrete format by explicitly prescribing their typographical layout and providing appropriate macros and style files. ${ }^{6}$ But the full change to a complete author generated typesetting via $\mathrm{T}_{\mathrm{E}} \mathrm{X}$ was certainly not immediate.

Even a few years later a bold stand by Managing Editor Michael W. Mislove was needed to require the use of some version of $\mathrm{T}_{\mathrm{E}} \mathrm{X}$ in preparing submissionsnowadays a self-understood practice for all authors publishing mathematics.

From the beginning the editorial board reflected the obvious fact that even in a specialized field like the area of semigroups there would be flourishing subspecialties competing for space and influence. A closer look at the comparatively complex structure of editorial board may reveal how this college of experts tried to represent the varied subspecialities and to channel the discussions on the functioning of the journal into constructive paths.

\footnotetext{
4 It is instructive to peruse the listing of the first 40 or 50 issues in the Lecture Notes series as it used to be reproduced in each of the early volumes in order to understand the wide acceptance of this concept of publication by many prominent authors of the period. As far as semigroups are concerned, it did take a while until the first volume on this subject appeared as no $\mathbf{4 2}$ in 1967.

5 Cf. Issue no. 1 in volume $\mathbf{1}$, two pages following p. 94.

6 One of the founding editors, BORIS M. SCHEIN, used to exhort authors to follow "comrade Murof's" instruction.
} 
The early history of the algebraic theory of semigroups prior to the emergence of Semigroup Forum is ably presented in the book [4] by C. HoLLINGS and its worthwhile extended review [11] by P. M. HIGGINS. These sources point out that much of it happened in the Soviet Union in an environment somewhat secluded from western mathematics. PAUL MOSTERT's article [13] on his historical research, supported by the recollection of those of us who were present at the memorable 1968 conference at Smolenice near Bratislava in Czechoslovakia, illustrates perfectly what a crucial point in the genesis of the journal it was and which developments led up to the organisation of this event. Indeed it was a key conference organized by ŠTEFAN SCHWARZ who was then the President of the Slovak Academy of Sciences. On the two sides of the Iron Curtain, whose last remaining gap was filled by the Berlin Wall in 1961, the field of semigroups could be cited as one field of mathematical specialisation in which two families of scholars had developed traditions largely separately on each side of that wall separating East from West. Literature existed in algebra and topology proving that a genuine and creative interest had developed in the area of semigroups. The book by E. S. LYAPIN [12] had been translated into English from the Russian original by the American Mathematical Society. In the West, the two volumes of the seminal work by A. H. ClifFORD and G. B. PRESTON [2] had appeared and were to be translated into Russian in 1972, so that a broad basis for the algebraic theory of semigroups clearly existed. An early tract by A.B. PAALMAN- DE MiRANDA [16] in 1964, in fact her dissertation, introduced the theory of topological semigroups into the monograph literature; it was much appreciated and cited by A. D. WALLACE at the time. In 1966, the more comprehensive book on compact topological semigroups by K. H. Hofmann and P. S. Mostert [10] and later, 1983 and 1986, the more pedagogical monographs by H. CARRUTH, J. Hildebrant, and R. J. Koch [1] demonstrated the presence of considerable research activity in the field of (mostly compact) topological semigroups. This line of investigation had developed in the school of A. D. WALLACE from the early fifties onwards, notably in the South of the US. ${ }^{7}$ In fact, in its early years, Semigroup Forum dedicated a whole volume to the pioneers CLIFFORD AND WALLACE ${ }^{8}$ on their 65th, respectively, 68th birthdays. The biographical essays in that volume, among other things, contain citations from their personal correspondence and from the authors' personal recollections which are accessible nowhere else. The article on WALLACE showed in a tree diagram how the early topological semigroup theory had been embedded into the mathematically famous school of topology following ROBERT LEE MOORE.

The early books from the sixties were unthinkable without rather solid activity of research articles in journals on both sides of the wall, an activity which is also documented in various sources from the subsequent decades. ${ }^{9}$ However, in 1968 , on this basis of the knowledge of the considerable literature on semigroups, lively discussions took place in Smolenice with the thrust that the "semigroup community"

\footnotetext{
7 Cf. e.g. [9] in Semigroup Forum 7.

$87,1974$.

9 For the side of topological semigroups see also e.g. [5,7,8], the last two in Semigroup Forum 50, resp.61.
} 
should have its own vehicle of communication, and so the persons present decided that one should work on producing some print medium for communicating the recent progress in the field. It was not entirely clear at the time, whether such a medium should be a journal in the classical format. Under the advice and influence of KLAUS PETERS it appeared at the time that a journal on the novel basis of a fast author-generated reproduction of texts might be ideal for the purpose. In retrospect, one observes that Semigroup Forum was in essence leading a trend for the development of specialized mathematical journals. In the course of its existence it established itself as one of the recognized sources of a continued tradition of research in the theory of algebraic, topological and analytical semigroups. Today, in the Journal Ranking of the Australian Mathematical Society for the Mathematical Sciences, the journal Semigroup Forum is ranked in the respectable category A. ${ }^{10}$

At the Smolenice Meeting in 1968, a picture was taken of almost all participants.

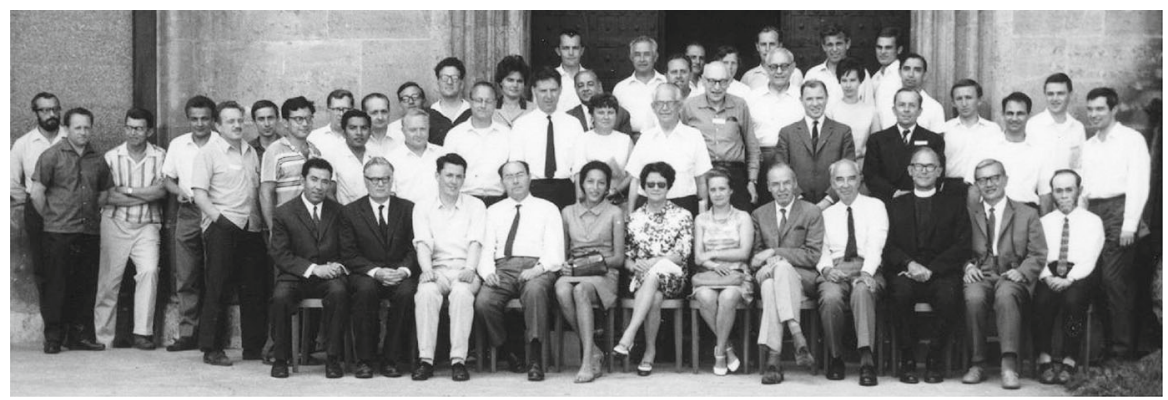

It soon became well known in semigroup circles since it provided a rather representative cross-section of the prominent semigroup community at this point in time. However, a conference photograph was first published in Semigroup Forum in Volume 50 in $1995^{11}$ in an essay honoring ŠTEFAN SCHWARZ and his important role in the birth of Semigroup Forum. Indeed, the Smolenice conference, which we nowadays consider as the founding conference of Semigroup Forum, had been convened by ŠTEFAN SCHWARZ. The published photo from that conference was kindly provided by LEV SHEVRIN.

The mentioned essay in volume 50 of Semigroup Forum is in fact an expanded version of K.H. HOFMANN's address at a conference in Kočovce, Slovakia, which was organized in celebration of ŠTEFAN SCHWARZ's 80th birthday and took place about a quarter of a century after the Smolenice convention. Here is also a photo of the participants of the Kočovce conference [3]:

\footnotetext{
10 The possible categories are $\mathrm{A}^{*}, \mathrm{~A}, \mathrm{~B}, \mathrm{C}$.

11 See [7], p. 126.
} 


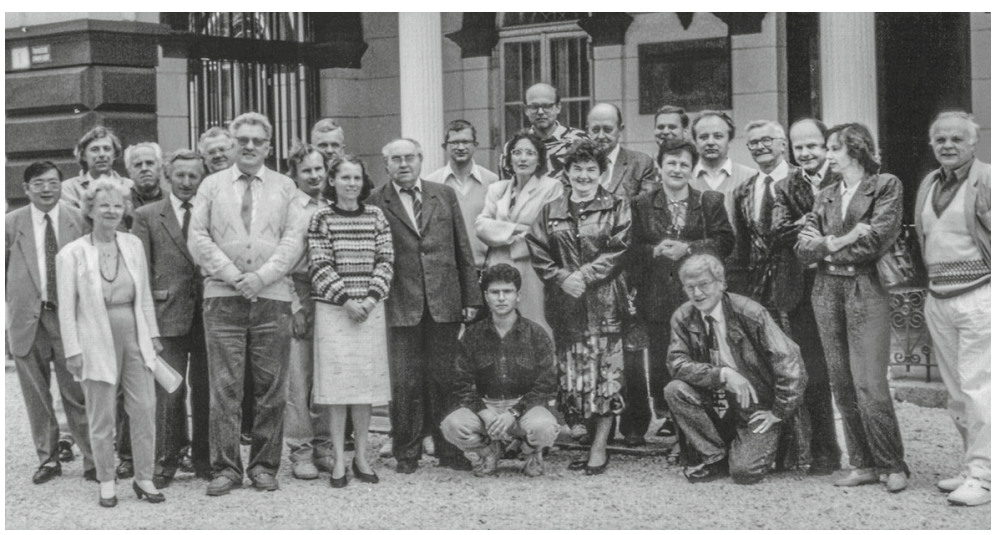

It had been PAUL MOSTERT's ambition to identify each and every one of the participants at the meeting in the Smolenice picture. He was surprisingly successful as his articles $[13,14]$ in this issue of Semigroup Forum show. Knowing his efforts all along, we had urged him to publish his research, but his failing health apparently prevented the full completion for the publication of all of his material up to this point. We are therefore really fortunate to be able to present to the readers of Semigroup Forum what he has collected, researched, and written.

The implementation of the "Smolenice Resolution" on the creation of some platform of publication on semigroup theory was assigned to the persons who were working in semigroups at that time at Tulane University in New Orleans under close cooperation with the semigroup contingent at Louisiana State University in the State capital Baton Rouge. During all of the sixties, as outside funding appeared rather readily available at that time, Tulane had been host to a steady stream of visitors in semigroup theory from the UK, France, Australia. The initiatives of A. H. CLIFFORD and A. D. WALlACE appeared to be instrumental. In a slightly different direction, in the context of their joint travels to Europe, K. H. Hofmann and P. S. Mostert, had established European links in that region which included contacts with Springer Verlag in Heidelberg, notably with KLAUS PETERS who had promoted those rather innovative ideas about publishing mathematics like the Springer Lecture Notes in Mathematics mentioned above, visibly successful following the idea, that new ideas should be published in statu nascendi-at a time when they are generated and perhaps are yet incomplete and possibly unpolished at the time. It was therefore natural that a founding editorial board would be created at Tulane University. It was understood that BORIS M. SCHEIN belonged to the founding members, yet also that the global political constellations were not conducive to his being officially included in this "managing" board at that location and time. On the first board of editors, the Managing Editors were A. H. Clifford, K.H. Hofmann, and P.S. Mostert, (all Tulane U., New Orleans) and the Members of the Board of Editors were D.R. BROWN (U. of Houston), P. Dubreil And M.- L. Dubreil- Jacotin (U. de Paris), L.M. Gluskin (U. of Charkov), Z. Hedrlín (Charles U. Prague), E. HEwITT (U. of Washington, Seattle), H.J. Hoehnke (Deutsche Akademie d.Wiss. Berlin), R.P. HunTER (Pennsylvania State U.), R. J. Koch (Louisiana State U., Baton Rouge), M. PeTrich (Pennsylvania State U.), L. RÉDEI (Hungarian Academy of Sciences, Budapest), J. RHODES 
(U. of California Berkeley), T. SAITÔ (Tokyo Gakugei U., Tokyo), B.M. SCHEIN (U. of Saratov), Š.ScHWARZ (Slovak Academy of Sciences, Bratislava), O. STEINFELD (Hungarian Academy of Sciences, Budapest), V.V. WAGnER (U. of Saratov), A.D. WALLACE (U. of Florida, Gainesville).

Acknowledgements We cordially thank ULRICH REIF of Darmstadt University of Technology for providing us with the Möbius band submonoid of the solid torus. Further we express our gratitude to Editor LÁsZLÓ MÁRKI for his careful scrutiny of our text and the two texts by PAUL STALLINGS MosterT, who allowed us to finalize his manuscripts for publication in this issue of Semigroup Forum. Acting as a careful and knowledgeable referee, MÁRKI added historical precision to these texts and rounded them off by contributing additional inputs of considerable factual interest.

\section{References}

1. Carruth, H., Hildebrant, J., Koch, R.J.: Introduction to Topological Semigroups I, II, Marcel Dekker, New York, 1983, vi+244pp., respectively, 1986, vii+195pp

2. Clifford, A.H., Preston, G.B.: The Algebraic Theory of Semigroups I and II. American Mathematical Society, Providence, RI, 1961, xv+224pp., respectively, 1967, xv+350pp.; Mir Moscow, 1972, 286pp., respectively, 422pp. (in Russian)

3. Grošek, O, Satko, L.: International Conference in Kočovce, May 29-31, 1994, Semigroup Forum 50, 121-122 (1995)

4. Higgins, P.M.: Review of [11], Math. Reviews, MathSciNet MR. 3222721, 3pp. (2019)

5. Hofmann, K.H.: Topological semigroups. History, theory, applications. Jahresber. Dtsch. Math. Ver. 78, 9-59 (1976)

6. Hofmann, K.H.: On an application of the work of D. E. Knuth to semigroups. Semigroup Forum 39, 117-124 (1989)

7. Hofmann, K.H.: From a topological theory of semigroups to a geometric one. Semigroup Forum 50, 123-134 (1995)

8. Hofmann, K.H.: On the history of topological and analytical semigroups - a personal view. Semigroup Forum 61, 1-26 (2000)

9. Hofmann, K.H., Koch, R.J., Mostert, P.S.: Alexander Doniphan Wallace on his 68th birthday. Semigroup Forum 7, 10-31 (1973)

10. Hofmann, K.H., Mostert, P.S.: Elements of Compact Semigroups. Charles E. Merrill, Columbus, OH, xiii+384pp. (1966)

11. Hollings, Ch.: Mathematics Across the Iron Curtain. A History of the Algebraic Theory of Semigroups, History of Mathematics, vol. 41. American Mathematical Society, Providence, RI, xii+441pp. (2014)

12. Lyapin, E.S.: Semigroups, Fizmatgiz, Moscow, 1960, 592pp. (in Russian); American Mathematical Society Translations, vol. 3, Providence, RI, v+447pp. (1963)

13. Mostert, P.S.: The Founding of the Semigroup Forum-On the 50th Anniversary its Formation, Semigroup Forum (this issue), 10pp. (2020)

14. Mostert, P.S.: A Front Row Seat: Štefan Schwarz and the Smolenice Meeting, Semigroup Forum (this issue), 7pp. (2020)

15. Murof, H.T.: see [6]

16. Paalman-de Miranda, A.B.: Topological Semigroups. Mathematical Centre Tracts, vol. 11, p. 169. Mathematisch Centrum, Amsterdam (1964)

Publisher's Note Springer Nature remains neutral with regard to jurisdictional claims in published maps and institutional affiliations. 